\title{
NUEVOS ÍDOLOS ANTROPOMORFOS CALCOLÍTICOS DE LA CUENCA MEDIA DEL GUADIANA
}

\section{NEW CHALCOLITHIC ANTHROPOMORPHIC IDOLS FROM THE MIDDLE GUADIANA BASIN}

\author{
por
}

\author{
JUAN JAVIER ENRÍQUEZ NAVASCUÉS
}

A. D. Enrique Vallespí, de quien tanto aprendimos.

RESUMEN

\section{ABSTRACT}

Palabras claves

\begin{abstract}
Se presentan cinco nuevas cabezas de ídolos antropomorfos calcolíticos de caliza marmórea y diversos fragmentos de otros, que proceden de cuatro yacimientos enclavados en la cuenca media del Guadiana. Junto a ellos un nuevo ídolo casi completo encontrado en Llerena. Con estos hallazgos se hace un repaso a los ídolos de silueta antropomorfa del Calcolítico peninsular y de manera especial se busca una mejor definición de los aparecidos en el citado marco geográfico
\end{abstract}

Here there are five new heads of anthropomorphic idols a several fragments which are from four different places in the middle basin of the Guadiana river, besides an almost complete idol found in Llerena. With these finds a revision of anthropomorphic idols from the peninsular Copper Age is made a those of the middle basin of the Guadiana river are examined especially

Ídolos calcolíticos antropomorfos. Cuenca Media del Guadiana (prov. Badajoz, Extremadura)

En la "Colección de Prehistoria" del Exmo. Ayuntamiento de Mérida se encuentra depositado un conjunto de fragmentos de ídolos antropomorfos de caliza marmórea entregado por D. José Jiménez Álvarez, que fueron encontrados en diversos yacimientos calcolíticos cercanos a dicha localidad. Estos hallazgos vienen a ampliar la dispersión hasta ahora conocida para esta clase de piezas en un área geográfica donde los llamados "ídolos" efectuados en caliza marmórea-y en especial los antropofomos-constituyen uno de los elementos más singulares, de manera especial por su gran abundancia en el yacimiento de la Pijotilla (Hurtado 1980 y1981). Se trata de hallazgos superficiales, pero sus lugares de procedencia corresponden en casi todos los casos a poblados de desiguales tamaños y de diferentes características tipológicas. 
En total son nueve fragmentos claramente antropomorfos, además de algunos otros que pudieron pertenecer igualmente a ídolos de silueta antropomorfa o tal vez a ídolos espatuliformes, y no faltan otras piezas no decoradas en forma de espátula e incluso quizá algún betiloide (fig. 2 y 3 ). De los antropomorfos destacan cinco cabezas encontradas en dos yacimientos distintos: Las Lomas y Trujillanos 2, mientras los fragmentos restantes pertenecen al tronco y en un caso a las extremidades inferiores. Fueron hallados en tres lugares diferentes, el citado de Las Lomas, Travieso y Villafranca de los Barros.

Por otra parte, incluimos también otro ídolo, esta vez en soporte de materia orgánica, encontrado así mismo de manera casual en la localidad de Llerena, por D. José Iñesta Mena, al considerar que se trata de una pieza de notable interés y algo distinta de las hasta ahora conocidas en la cuenca media del Guadiana. Con estas nuevas piezas son siete los lugares de la Cuenca media del Guadiana donde, hasta el momento, se han producido hallazgos de este tipo de ídolos (fig. 1), lugares de los cuales seis son con seguridad antiguos poblados.

\section{LAS PIEZAS DE CALIZA MARMÓREA (fig. 2-3 y lám. 5).}

Excepto la procedente de Llerena, que se describirá más adelante, las demás son en caliza marmórea, rotas y algunas de ellas algo rodadas. Sus caracteres tecnomorfológicos son similares a los ejemplares conocidos de la Pijotilla y Rena en la misma provincia de Badajoz.

1. Cabeza $n^{\circ} 1$ procedente de Las Lomas (Mérida), con múltiples concreciones en la superficie. Ofrece peinado, frente, cejas, órbitas oculares, nariz, tres líneas de tatuaje facial, peinado posterior y parte del cuello. Mide 4,6x3,3×2,7 cm (fig. $2 \mathrm{n}^{\circ} 1$; lám. 2)

2. Cabeza $n^{\circ} 2$ procedente de Las Lomas (Mérida), con peinado, frente, órbitas oculares, nariz, dos líneas de tatuaje facial, indicación de orejas, peinado posterior y cuello. Mide 2,8x2,2x2,3 cm (fig. $2 \mathrm{n}^{\circ} 3$ )

3. Cabeza $n^{\circ} 3$ procedente de Las Lomas (Mérida), rota en la parte derecha de la cara, pero que deja apreciar el peinado, frente, cejas, órbita ocular, dos líneas de tatuaje facial, indicación de orejas, peinado posterior y existencia de cuello. Mide 2,7x2,5 cm (fig. $2 \mathrm{n}^{\circ} 5$; lám. 3)

4. Cabeza $\mathrm{n}^{\circ} 4$ procedente de Trujillanos 2 (Trujillanos). Ofrece peinado, frente, cejas, órbitas oculares, nariz, dos líneas de tatuaje facial, indicación de orejas, peinado posterior y cuello. Mide 3,6x2,5x2,8 cm (fig. $2 \mathrm{n}^{\circ} 2$ ).

5. Cabeza $n^{\circ} 5$ procedente también de Trujillanos 2 (Trujillanos), rota en el tercio inferior de la cara, con peinado anterior, frente, órbitas oculares, nariz, dos líneas de tatuaje facial, indicación de orejas y peinado

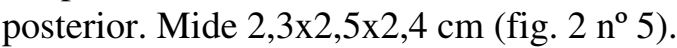

6. Tronco de figura antropomorfa con representación de los brazos enfrentados en la cara anterior, dejando un hueco de sección en V entre las manos, y decoración lineal en el reverso. Procede de Villafranca de los Barros. Mide 5,4x4,5x2,3 cm (fig. $3 \mathrm{n}^{\circ}$ 1)

7. Tronco de figura antropomorfa muy rodada, tal vez con indicación de los brazos en el anverso y restos de líneas incisas en el reverso. Procede de Las Lomas (Mérida) y mide 4,5x4,3x2,2 cm (fig. $3 \mathrm{n}^{\circ} 2$ )

8. Parte del tronco y arranque de las extremidades inferiores de figura antropomorfa, con las piernas unidas y en la cara anterior una "v" que parece marcar el sexo de la figura. Procede del yacimiento de Travieso (Valdetorres). Mide 6,7x2,3x1,4 cm (fig. $3 \mathrm{n}^{\circ} 4$ ).

9. Fragmento de tronco de figura humana muy deteriorado, que parece tener la representación de los brazos, procedente del mismo lugar de Travieso (Valdetorres). Mide 3x3,7x3,7 cm (fig. $3 \mathrm{n}^{\circ} 3$ ).

10-16. Fragmentos de más difícil asignación, algunos de ellos decorados (fig. $3 \mathrm{n}^{\circ} 5-7$ ), tres espatuliformes lisos (fig. $3 \mathrm{n}^{\circ} 8-10$ ) y un posible fragmento betiloide (fig. $3 \mathrm{n}^{\circ} 11$ ). Fueron encontrados todos de Las Lomas (Mérida). 


\section{LOS YACIMIENTOS}

Son cuatro los lugares de procedencia de estas piezas, tres de los cuales se corresponden con sendos poblados calcolíticos, donde se han encontrado otros materiales tipológicamente encuadrables en un Calcolítico pleno y final. El cuarto por su parte es un enclave de difícil valoración superficial (fig. 1).

1. El poblado de Las Lomas (término municipal de Mérida) se localiza en un alto sobre el arroyo Albarregas, junto al antiguo camino de Mérida a Trujillanos, justo detrás del complejo hotelero de Las Lomas al que se accede por la antigua carretera nacional V. El lugar se encuentra muy arrasado, con una área de hallazgos superficiales en torno a la Ha. de extensión. Además de las tres cabezas, del fragmento del tronco y del resto de fragmentos de ídolos y objetos en caliza marmórea, se recogieron, y depositaron en la anteriormente citada colección, otros fragmentos cerámicos, piedras talladas y pulidas y algunos objetos de cobre entre los que destaca un cincel completo de sección rectangular, un punzón biapuntado de sección también rectangular, un hacha de filo destacado y diversos fragmentos de punzones. Aunque no se habían hecho referencias hasta ahora a materiales de este poblado, su existencia había sido recogida en un reciente trabajo (Enríquez 1997, fig. 1 no 3).

2. El denominado Trujillanos 2 (término municipal de Trujillanos) es otra elevación, en este caso más suave, sobre el pequeño arroyo de Los Canchales, con una área de dispersión superficial no muy extensa, entre 0,5 y $1 \mathrm{Ha}$., con los materiales de superficie encontrados en la ladera Oeste. De ahí proceden las dos cabezas reseñadas y junto a ellas se hallaron otra serie de piezas fundamentalmente cerámicas y líticas, de tipología semejante a la que ofrecen los poblados del Calcolítico avanzado de la comarca de Mérida. Unos $500 \mathrm{~m}$ al Este se sitúa otro poblado, que se denominó Trujillanos, cuyos materiales de superficie presentan unos rasgos tipológicos que parecen indicar una fase anterior (Enríquez 1990,174 y ss.). Como en el caso de Las Lomas, el yacimiento había sido recogido pero no se habían referenciado materiales (Enríquez 1997, fig. $1 \mathrm{n}^{\circ}$ 5).

3. El poblado de Travieso (término municipal de Valdetorres) se encontraba inédito y su ubicación es la de un altozano destacado sobre el arroyo Chaparral, muy cerca de la entrada a la localidad de Valdetorres. El área de dispersión de materiales es pequeña, no supera las 0,5 Ha., y en ella se recogieron también, además de los dos fragmentos de troncos de ídolos, diversos materiales cerámicos y líticos así como un cincel de sección rectangular y otros fragmentos amorfos de cobre.

4. Por último, un fragmento de tronco de figura antropomorfa se halló en el término municipal de Villafranca de los Barros, en el denominado Cerro de la Cañería, junto al lugar en el que la carretera local de Villafranca a Aceuchal atraviesa la vía férrea de Mérida a Zafra. Allí, en la margen izquierda de dicha carretera, se situaba una estructura tumular bien destacada del entorno pero que hoy en día se encuentra prácticamente arrasada, aunque hasta hace unos años constituía un verdadero montículo. Su valoración arqueológica resulta ahora problemática, puesto que a pesar de que había materiales arqueológicos calcolíticos en el entorno del montículo, su extensión superficial se circunscribía a un espacio pequeño mas o menos coincidente con sus límites y el número de los mismos era escaso y casi exclusivamente se trataba de fragmentos cerámicos. Además más abundantes resultaban los materiales protohistóricos, de carácter orientalizante, recogidos y en buen número en dicho lugar (Duque Espino, en prensa)

Estos cuatro lugares se unen así a los yacimientos de La Pijotilla y la Habilla en Rena, el primero el mayor y más rico en artefactos de los conocidos hasta ahora en la zona y el segundo un poblado en llano fluvial de tamaño mediano. El séptimo lugar en el que se ha encontrado un ídolo de silueta antropomorfa es Llerena, en este caso algo diferente a los anteriores. 


\section{EL ÍDOLO DE LLERENA (fig. 4 y lám. 4)}

Este ídolo, encontrado y dado a conocer por D. José Iñesta Mena (1995), se halló de manera casual en el relleno de un área urbana de la localidad de Llerena, cuya tierra procedía del mismo pueblo, en concreto de un espacio anejo a la antigua muralla conocido como el Huertecillo, junto al actual paseo de S. Antón. En la zona del Huertecillo aparecieron materiales calcolíticos en los inicios de unas obras para una nueva urbanización a finales de 1989, lo que motivó la realización de una excavación de urgencia en el lugar, gracias a la cual pudo comprobarse como allí hubo un poblado calcolítico muy afectado en cuanto a su estado de conservación por las obras de la propia muralla así como por otras construcciones más modernas. Con todo se pudo constatar la existencia de subestructuras excavadas en la roca caliza, aunque muy deterioradas, a las que se asociaban materiales encuadrables en un calcolítico pleno (Enríquez e Iñesta 1995). A tenor de los hallazgos entonces detectados no parecía que se tratase de un poblado de grandes dimensiones, aspecto éste que parece confirmarse, puesto que a unos $200 \mathrm{~m}$ al N . en nuevos sondeos efectuados en la manzana del Portillo de Curtidores ningún resto antiguo apareció, de igual manera que tampoco en otros efectuados para obras en la zona E. de la localidad. Al O. de Llerena, en el Ejido de S. Marcos, D. José Iñesta encontró piedras talladas y pulidas pero sin indicios de elementos de habitación. Parece así que se trata de un asentamiento pequeño o en todo caso mediano, que aprovechaba un suave relieve junto a un manantial, donde más tarde se levantó el lienzo N.O. de la muralla de Llerena.

La pieza (fig. 4) aprovecha el lado convexo como anverso para acentuar el relieve de la representación y el lado más plano como reverso. Se encuentra rota a la altura de las piernas en su tercio inferior y mide $10,2 \mathrm{~cm}$ de longitud por $2,5 \mathrm{~cm}$ de anchura máxima en los hombros y tiene un grosor de $1,5 \mathrm{~cm}$ a la altura de la cintura. Presenta una talla de rebaje y un pulido de las superficies, destacando en altorrelieve el objeto que porta entre las manos. Las incisiones que se aprecian en toda la pieza son de sección en $V$ pero de desigual profundidad y anchura. Así las piernas aparecen separadas a base de una $\mathrm{V}$ amplia y profunda, mientras en los brazos y peinado la incisión es también profunda pero más estrecha, con menor anchura aún en las cejas y tatuaje facial.

La cabeza tiene nueve incisiones profundas marcando la disposición lineal del peinado y, bajo una corta frente, las cejas aparecen a base de incisiones continuas en cuatro trazos en zig-zag horizontal, dos por ceja. Las órbitas oculares son dos oquedades profundas, que parecen efectuadas para contener algún relleno, separadas por la nariz, de poco relieve lateral pero frontalmente bien señalada por dos incisiones que parten a la altura del lagrimal. El tatuaje facial consta de dos líneas en zig-zag vertical y ni las orejas ni el cuello están siquiera insinuados. El tronco, de forma trapezoidal alargada, presenta la consabida señalización de los brazos unidos al cuerpo, mientras las manos enfrentadas se recogen sin que ningún detalle anatómico se precise. Sostenido por ellas está representado de manera muy nítida un objeto de forma trapezoidal con un soporte o mango individualizado por su mayor estrechez y cuatro líneas incisas horizontales y paralelas. En el arranque de las extremidades inferiores se encuentra marcado en relieve el sexo masculino de la figura, mientras la separación entre ambas piernas se concreta mediante una incisión ancha y profunda. Por el reverso el peinado o tocado desarrolla un zig-zag dorsal que cae desde la cabeza hasta la cintura, los gluteos se encuentran marcados y realzados y más abajo otra línea ancha vertical separa las piernas.

\section{COMENTARIO}

La relación formal e ideotécnica de estos nuevos ídolos antropomorfos de la Cuenca media del Guadiana con los ya conocidos de El Malagón (Arribas 1977), Valencina de la Concepción (Fernández Gómez y Oliva 1980), Marroquíes Altos y Torre del Campo (Blanco 1962), Esperilla (Hurtado y Perdigones 1981) 
fortín I de Los Millares etc. no precisa de muchos comentarios, aunque sí que es reseñable su especial vinculación, y no solo geográfica, con los ejemplares de caliza marmórea de La Pijotilla y Rena (Hurtado 1980; Hurtado y Perdigones 1984). Y es precisamente la Cuenca media del Guadiana el área que concentra hoy por hoy el mayor número y la mayor dispersión de ídolos con figura antropomorfa completa del Calcolítico peninsular, aunque bien es cierto que gracias sobre todo a los ejemplares de la Pijotilla. A pesar de ello, con las nuevas piezas aquí presentados se vienen a poner de relieve inicialmente dos aspectos de interés. Primero la extensión de los ídolos antropomorfos de caliza marmórea por un total de 6 lugares, hasta ahora, en la línea del Guadiana medio: La Pijotilla (Badajoz), Las Lomas (Mérida), La Habilla (Rena), Trujillanos 2 (Trujillanos), Travieso (Valdetorres) y Villafranca de los Barros, lo cual parece reforzar el papel del asentamiento de la Pijotilla en esta área geográfica dentro de la dinámica de concentración /distribución de elementos de especial significación socio-cultural (Hurtado 1995: 74). En segundo lugar es igualmente destacable como esta clase de ídolos no solo se ciñen a grandes poblados, sino que su dispersión alcanza también a asentamientos de tamaño mediano e incluso pequeño, como Trujillanos 2 y Travieso, situados tanto sobre laderas de suaves colinas como en altozanos destacados, sin ser éstos en ningún caso los puntos más destacados del paisaje. Ello significa que su extensión por distintos lugares posee mayor variabilidad de lo que inicialmente podría pensarse y ahonda además en como la red de poblamiento se vincula de manera compleja a la circulación de materias primas determinadas -caliza marmórea en este caso- y a productos transformados de uso no primario o subsistencial, tanto desde el punto de vista estrictamente material como ideológico (García Sanjuán y Hurtado 1997: 143).

Más espinosas son otras cuestiones. Entre ellas el verdadero significado de los llamados ídolos, ya tratado en reuniones recientes (Hurtado dtor. 1995), o también el de una explicación del "fenómeno" de la antropomorfización de los ídolos como elementos de complejidad social y reflejo de cambios ideológicos, aspecto que se presenta interligado muy posiblemente a otras formas expresivas y a conceptos de gran dinamismo interno. La valoración que a este respecto han tenido los ídolos antropomorfos calcolíticos peninsulares a lo largo del tiempo refleja bastante bien las actitudes de las líneas de investigación historiográficas que se han sucedido sobre el Calcolítico peninsular. Bien conocida es así la gran abundancia de figurillas antropomorfas en el Neolítico y primeras etapas metalúrgicas de todo el Mediterráneo (Guilaine 1981: 177) y también cómo, a propósito de los peninsulares, ya Blanco apuntara que no tenían por qué representar influencias del cercano oriente y constituirían el final de un proceso de humanización de la divinidad (Blanco 1979: 42 y 46). Por los mismos años Arribas señalaba como los paralelos formales no tienen porqué implicar contactos (Arribas 1977: 72) y, poco después, Hurtado los consideró no importados aunque los ídolos serian la materialización de un concepto religioso común en el Mediterráneo (Hurtado 1980: 189 y 197). También conocida es la propuesta, entre otros, de Fernández Miranda sobre las cuestiones orientales acerca de la "difusión punteada a través de la transmisión de ideas" (Fernández Miranda 1985). Por contra, y como representantes de otros puntos de vista más anclados en el difusionismo tradicional, Fernández Gómez y Oliva defendían una relación con los ídolos cicládicos afirmando que "hay una elocuente unanimidad en todos los autores en buscar en el Mediterráneo oriental el origen y precedentes inmediatos de estos ídolos antropomorfos" (Fernández Gómez y Oliva 1980: 38).

Pero el antropomorfismo no era solo un fenómeno constatable en los ídolos calcolíticos, sino constatado también en los ajuares y estelas megalíticas y en el arte rupestre, con representaciones de la figura y silueta humana que poseían atributos a veces compartidos. También, comprobada estaba la confluencia de algunas de estas manifestaciones en el espacio y en el tiempo, como por ejemplo en La Pijotilla o Valencina de la Concepción donde junto a ídolos calcolíticos aparecieron ídolos placa con atributos antropomorfos. No está pues de más recordar aquí como, entre otros, Bécares resaltó el hecho de que las variedades tipológicas pudieran enmascarar en parte una uniformidad conceptual en los ídolos peninsulares, incluidos los de la pintura rupestre (Bécares 1990: 87). Por otro lado, Bueno, al tratar de la figura humana en el megalitismo 
occidental de la península Ibérica, defendió el origen de las estelas antropomorfas ibéricas en el arte megalítico y sobre todo en los ídolos placa antropomorfos, todo ello dentro de un amplio contexto de expresiones megalíticas que comprende grabado, pintura, decoración cerámica y arte mueble "en conexión con Europa occidental durante la $2^{\mathrm{a}}$ mitad del III milenio" (Bueno 1990: 86-87). De todos modos, la particularidad o singularidad que presentaban los ídolos antropomorfos calcolíticos era, como señalaron Hurtado y Perdigones (1984: 54 y 58), que sus variedades estilísticas no implicaban evolución tipológica y que, al contrario que los cicládicos, no evidenciaban un proceso evolutivo de formación.

Esta serie de valoraciones, y otras propuestas que al respecto también podrían citarse, recogen para el fenómeno de la antropomorfización consideraciones más o menos explícitas de referencia orientalista o mediterránea, los más, o bien occidentalista, matizables según autores, pero donde subyace siempre un transfondo de índole sacro-mágico-religiosa, no siempre aceptado (Chapman 1991: 61). No faltan sin embargo otras perspectivas que no se agotan en la vaga referencia a lo mágico-religioso, entre las que cabe resaltar la que apuesta por una relación de los ídolos antropomorfos calcolíticos con "una heroización narrativa del liderazgo" (García Sanjuán y Hurtado 1997: 148), "un nuevo concepto que comienza a hacerse sentir en la estructura social y que sería la figura del jefe o guerrero" (Hurtado 1995: 74). Otras, no obstante, afirman que "parecen no representar a determinados agente sociales donde exista una individualización de los rasgos-circunstancias más destacados de los mismos, sino más bien a ideas, conceptos que se esquematizan y mediante los cuales se representa una parte por el todo" (Escoriza 1991-92: 155).

D’Anna, en un estudio ya clásico, y también criticado, analizó las estelas antropomorfas del sur de Francia y señaló representaciones que también tienen los brazos a la altura de la cintura, nariz sin boca, tatuaje, peinado o pelucas en zig-zag etc. -aunque con otros detalles iconográficos propios-y concluyó que la comparación iconográfica es estéril y no permite ninguna conclusión definitiva. Y aunque insiste en lo difícil que es establecer relaciones entre lo pintado, grabado, esculpido etc. alude a un mismo fenómeno de antropomorfización en lo ideológico, que no en lo iconográfico, que a veces confluyó geográfica, cronológica y culturalmente con lo megalítico, pero con evolución diferente (D’Anna 1977: 234). Más recientemente, Briard señalaba en relación al tema que se trató de un fenómeno general con variantes donde toda extrapolación abusiva sería una negación de la variedad de corrientes de pensamiento (Briard 1993: 77). Por consiguiente, la antropomorfización se nos presenta como un elemento más de un dinamismo simbólico bien constatado a finales del III milenio que, al igual que otros, resulta de difícil solución (Gallay 1986: 198).

Sea como fuere, lo que parece deducirse de los ídolos con silueta antropomorfa del Calcolítico peninsular en concreto, es que no resultan ajenos a formas expresivas muy extendidas geográficamente, formas que concretan ideas y conceptos generales también muy extendidos. Su contexto de integración socio-económico y cultural, al margen de que se vinculen a áreas funerarias y domésticas, es lo que hace pensar que tal vez formen parte de un proceso de autoafirmación del liderazgo, como ya se ha dicho, y por ello a veces lleven elementos de estatus y prestigio como el que portan entre las manos el de Llerena y el de Marroquies Altos. Recordemos como la tradición figurativa peninsular de origen megalítico se enriqueció a veces con armas como elemento distintivo en estelas y estelas-menhir (Bueno 1983: 157) y que la interpretación de la figura humana, como en el propio caso de las estelas según Almagro Gorbea, hay que entenderla como consecuencia de la jerarquización creciente de las sociedades que se inició en el Calcolítico y que siguió durante la E. del Bronce (Almagro Gorbea 1993: 133). Por todo ello, quizá los ídolos de silueta antropomorfa resulten así el fruto de un proceso conceptual interno cuya representación plástica pudo estar estimulada iconográficamente según se aprecia en determinados rasgos morfológicos. Unos rasgos que ofrecen semejanzas pero también diferencias con respecto a los que caracterizan a otras expresiones tanto foráneas como de la propia tradición, elementos en unos casos compartidos con ellas y en otros más particulares, de tal modo que parece existir una cierta unidad conceptual dentro de un contexto expresivo amplio y variado donde como tal se incardinan. 


\section{LOS ÍDOLOS ANTROPOMORFOS DEL GUADIANA MEDIO DENTRO DEL CONTEXTO DE LOS ÍDOLOS ANTROPOMORFOS PENINSULARES}

Ya en algunas ocasiones se han ido apreciando diferencias zonales y regionales que pudieran ayudar a una mejor definición por grupos y áreas culturales. Es el caso por ejemplo de la disposición de los brazos, que en el Guadiana medio se presentan enfrentados mientras los de Jaén y Valencina lo hacen cruzados, o de la preferencia en la misma área del Guadiana por la caliza marmórea como soporte (Hurtado y Perdigones 1984: 54-55). Para adentrarnos un poco más en el análisis de la estructura formal de estos y otros ídolos antropomorfos peninsulares, hemos elegido una serie de elementos, cuya consideración y justificación implica una cierta subjetividad, pero que pretende responder tanto a un plano conceptual (cómo se concibe la estructura del llamado ídolo antropomorfo completo) como formal (qué variantes técnicas y formales presenta el tratamiento del mismo tema). Estas variables escogidas son: a) materia prima, b) longitud, c) sexo, d) cara/tatuaje facial, e), peinado anterior, f) peinado posterior, g) brazos y manos, h) piernas y tronco, i) otros y j) contexto. El análisis lo hemos aplicado únicamente a aquellos ejemplares que sabemos que tuvieron una silueta antropomorfa completa, dejando fuera por tanto toda la serie de ídolos e idolillos que carecen de ella, así como fragmentos de otros figurillas que entran dentro de la consideración de antropomorfos (Almagro Gorbea 1973: 247 y ss.) pero cuya morfología y silueta es desconocida o bien diferente. La representación de las citadas variables queda recogida en los cuadros 1 y 2

\begin{tabular}{|c|c|c|c|c|c|}
\hline & Torre del Campo & Marroquíes A. & Malagón & Valencina 1 & Valencina 2 \\
\hline materia prima & marfil & marfil & marfil & hueso & hueso \\
\hline longitud & 13,45 & 13,3 & 16,6 & 15,3 & 11,5 \\
\hline sexo & $\mathrm{M}$ & no claro $(\mathrm{M})$ & $\mathrm{M}$ & $\mathrm{M}$ & $\mathrm{M}$ \\
\hline tatuaje facial/cara & $\begin{array}{c}\text { Dos surcos } \\
\text { cejas marcadas }\end{array}$ & $\begin{array}{l}\text { Dos surcos } \\
\text { Oreja. Roto }\end{array}$ & & $\begin{array}{c}\text { Dos surcos } \\
\text { cejas marcadas }\end{array}$ & $\begin{array}{c}\text { Dos surcos } \\
\text { cejas marcadas }\end{array}$ \\
\hline peinado anterior & $\begin{array}{c}\text { surge frente } \\
\text { sin franja } \\
\text { sin zig-zag }\end{array}$ & $\begin{array}{l}\text { surge frente } \\
\text { sin franja } \\
\text { con zig zag }\end{array}$ & & $\begin{array}{l}\text { surge frente } \\
\text { franja central }\end{array}$ & en sierra \\
\hline peinado posterior & zig-zag & zig-zag & & zig-zag & zig-zag \\
\hline manos y brazos & $\begin{array}{c}\text { cruzadas } \\
\text { poco marcados }\end{array}$ & $\begin{array}{c}\text { objeto } \\
\text { poco marcados }\end{array}$ & & cruzadas & cruzadas \\
\hline tronco y piernas & 1 pieza, p. unidas & $\begin{array}{c}2 \text { piezas, } \\
\text { algo separadas }\end{array}$ & algo separadas & 1 pieza, unidas & 1 pieza, unidas \\
\hline otros & & & articulado & & \\
\hline contexto & cueva & $\begin{array}{c}\text { tumba? } \\
\text { poblado grande }\end{array}$ & $\begin{array}{c}\text { cabaña } \\
\text { poblado amur. }\end{array}$ & $\begin{array}{c}\text { pozo } \\
\text { poblado grande }\end{array}$ & $\begin{array}{c}\text { pozo } \\
\text { poblado grande }\end{array}$ \\
\hline
\end{tabular}

\section{Cuadro 1. Ídolos antropomorfos de Andalucía}




\begin{tabular}{|c|c|c|c|c|c|}
\hline & Pijotilla 1 & Pijotilla 2 & Rena & Llerena & Otros \\
\hline Materia prima & caliza marmórea & caliza marmórea & caliza marmórea & Hueso/marfil & caliza marmórea \\
\hline Longitud & 14 & 14 & 18,4 & 10,2 & \\
\hline Sexo & $\mathrm{M}$ & $\mathrm{F}$ & $\mathrm{M}$ & $\mathrm{M}$ & \\
\hline Tatuaje facial/cara & $\begin{array}{l}\text { Dos surcos } \\
\text { oreja, cuello }\end{array}$ & $\begin{array}{l}\text { Tres surcos. } \\
\text { Cejas orejas, } \\
\text { cuello }\end{array}$ & $\begin{array}{c}\text { Dos surcos. } \\
\text { Cejas orejas, } \\
\text { cuello }\end{array}$ & $\begin{array}{c}\text { Dos surcos } \\
\text { Cejas }\end{array}$ & $\begin{array}{c}2 \text { y } 3 \text { surcos } \\
\text { oreja(-1), cuello }\end{array}$ \\
\hline peinado anterior & $\begin{array}{c}\text { frente y franja } \\
\text { central }\end{array}$ & $\begin{array}{c}\text { frente y franja } \\
\text { central }\end{array}$ & $\begin{array}{c}\text { frente y franja } \\
\text { central }\end{array}$ & $\begin{array}{l}\text { en sierra, sin } \\
\text { apenas frente }\end{array}$ & $\begin{array}{c}\text { frente y franja } \\
\text { central }\end{array}$ \\
\hline peinado posterior & zig-zag & zig-zag & zig-zag & zig-zag & \\
\hline manos y brazos & $\begin{array}{c}\text { enfrentados } \\
\text { cavidad central }\end{array}$ & $\begin{array}{c}\text { enfrentados } \\
\text { cavidad central }\end{array}$ & $\begin{array}{c}\text { enfrentados } \\
\text { cavidad central }\end{array}$ & objeto & \\
\hline tronco y piernas & 1 pieza & 1 pieza, unidas & 1 pieza & 1 pieza, unidas & \\
\hline otros & incompletos & $\begin{array}{l}\text { incompletos } \\
\text { decoración }\end{array}$ & incompleto & incompleto & cabezas incompl. \\
\hline contexto & $\begin{array}{c}\text { s/c } \\
\text { poblado grande }\end{array}$ & $\begin{array}{c}\text { s/c } \\
\text { poblado grande }\end{array}$ & $\begin{array}{c}\mathrm{s} / \mathrm{c} \\
\text { pobl. mediano }\end{array}$ & $\begin{array}{c}\mathrm{s} / \mathrm{c} \\
\text { pobl. med/pequñ. }\end{array}$ & $\begin{array}{c}\text { s/c } \\
\text { poblado var. }\end{array}$ \\
\hline
\end{tabular}

\section{Cuadro 2. Ídolos antropomorfos del Guadiana medio.}

De la contrastación cruzada de los datos contenidos en los cuadros 1 y 2 se deducen fundamentalmente una serie de consideraciones en distintos órdenes: En primer lugar la variedad tipológica de los yacimientos de procedencia: poblados grandes como la Pijotilla, Valencina de la Concepción o Marroquies Altos, poblados más pequeños como la Habilla, Malagón o Las Lomas. Variedad también en cuanto a la territorialidad y diferente articulación de estos yacimientos en el paisaje, variedad así mismo en lo que se refiere a las estructuras conocidas de esos mismos yacimientos, unas veces con restos de murallas por ejemplo y otras en las que al menos éstas no constan. Variedad que igualmente se vuelve a mostrar en lo que concierne a los contextos, cuando los hay: cueva, cabaña, pozos etc. Dentro de esa diversidad, no puede dejarse de recordar la bien conocida abundancia y riqueza de esta clase de ídolos, y de otros tipos, en el yacimiento de La Pijotilla, de cuyo entorno empiezan a conocerse piezas similares que tienen en él su principal referente y no sólo geográfico como se ha comentado antes.

En cuanto a la materia prima, la preferencia de la caliza marmórea en el área del Guadiana medio (Pijotilla, Rena, Las Lomas etc.), del marfil en Andalucía oriental y del hueso en Valencina. El marfil como materia prima exótica se presenta también en el S.E. peninsular asociado a otros elementos destacados de la cultura material como sandalias o peines, mientras la caliza marmórea es muy utilizada en el S.O. para la fabricación de ídolos muy variados, recipientes y vasos a los que a veces se ha señalado como elementos votivos (Gonçalves 1997). El hueso tampoco carece de asociaciones a otros elementos de prestigio como peines, tubos y vasos decorados. De este modo, y al margen de las preferencias zonales señaladas, con estas materias primas en que están fabricados y con técnicas escultóricas muy similares parece que se quisiera resaltar la entidad de estas representaciones. Ciertamente hay figuras antropomorfas en otros materiales como el barro cocido, pero sin negar su carácter antropomorfo no participan de los rasgos iconográficos definitorios de este grupo con la silueta y figura completa a base de las indicaciones anatómicas señaladas anteriormente como las variables morfológicas más evidentes conceptual y formalmente. Parece pues que con la materia prima se quiso realzar este grupo concreto de figurillas. 
Los de piedra son los que alcanzan mayor longitud pese a estar fragmentados todos los que conocemos. También son los que ofrecen con mayor claridad figuraciones femeninas (La Pijotilla y Travieso), que en el caso de ejemplares de La Pijotilla presentan decoración frontal en el tronco. Poseen además otra serie de rasgos compartidos casi siempre y que no se repiten en los otros: cuello bien señalado, orejas marcadas (que sí están en Marroquies Altos y faltan en el ejemplar $n^{\circ} 1$ de las Lomas) y peinado anterior que parte de una franja central, los brazos están enfrentados como ya se dijo y además cabe resaltar, como ya hiciera Bécares para los ejemplares de la Pijotilla (Bécares 1990: 90), que poseen a la altura de las manos un hueco triangular como para soportar algún elemento. Este rasgo adquiere mayor consistencia al comprobarse como hay ídolos de esta clase que llevan objetos incorporados ahí con claridad (¿un arma como en el caso de las estelas?), tal y como puede apreciarse en el de Marroquíes Altos y en el de Llerena. Algún que otro rasgo más, quizá de menor rango, puede también señalarse y así solo en la Pijotilla y las Lomas hay tres surcos marcando el tatuaje facial -aunque en cabezas de barro cocido como una de Valencina también son tres- etc.

La distribución de los ídolos antropomorfos de caliza marmórea, con esas características específicas señaladas, se ciñe fundamentalmente al Guadiana medio como se ha repetido en diversos momentos, pero no faltan ejemplos de fragmentos fuera de la zona que sin embargo participan de idénticos rasgos. Es el caso de la cabeza de Esperilla (Arcos de la Frontera, Cádiz) con orejas, cuello y franja central en el peinado anterior. El de Llerena sin embargo, sobre soporte de materia orgánica, sin cuello ni insinuación de orejas, con las piernas unidas y peinado de la cabeza en sierra responde a una morfología muy cercana a los ídolos andaluces y de manera especial se parece $a^{\circ} n^{\circ} 2$ de Valencina. De este modo el hecho de que la cabeza de Esperilla ofrezca rasgos semejantes a las de los ídolos del Guadiana medio o el que el de Llerena posea rasgos similares a los de Valencina, no son mas que ejemplos de como esta clase de objetos no fueron ajenos en absoluto a la serie de interrelaciones e intercambios conceptuales y materiales entre las diferentes áreas y círculos geográfico-culturales del mediodía peninsular durante el Calcolítico

Por su parte, los que presentan hueso o marfil como materia prima de soporte suelen carecer de cuello y orejas, excepto el de Marroquies Altos, la disposición del peinado anterior es también diferente a los de caliza marmórea, salvo el $\mathrm{n}^{\circ} 1$ de Valencina, y las piernas se representan unidas. Puede señalarse además como es en Andalucía oriental donde de momento se documentan los ídolos articulados y como los rasgos de los ídolos de silueta antropomorfa de esta zona geográfica están más cercanos a los que ofrecen los de Valencina y Llerena.

Pero en lo que todos coinciden es en la disposición en zig-zag del tocado o peinado posterior, en resaltar las órbitas oculares -que tal vez tuvieran a veces algún elemento encajado y que casi siempre poseen las cejas señaladas- $y$ en marcar bien el tatuaje facial, elemento este acerca del cual se ha señalado su importancia no solo ornamental sino también simbólica (Hurtado 1981: 86). De ahí que los ojos -y casi siempre su resalte mediante las cejas- el tatuaje facial y el peinado o tocado resulten los caracteres más relevantes de estas figuraciones antropomorfas peninsulares, en tanto que siempre aparecen representados. Rasgos que sin embargo no les son exclusivos, sino que por el contrario se aprecian e incluso caracterizan a otras clases o tipos de ídolos muy variados. Pero aquí la función de esos elementos parece ser que es la de singularizar o realzar la representación antropomorfa en si. Lo que hacen es resaltar por tanto el propio hecho antropomórfico. Y éste es el atributo más importante, al que se supeditan o complementan todos los demás: el antropomorfismo y dentro de él la actitud similar que se aprecia en todas las figuras conocidas. De este modo el carácter antropomorfo y la actitud de la figura son al final las señas de identidad fundamentales. Unas señas o convencionalismo plástico dentro del cual el elemento masculino desarrolla o posee un especial protagonismo frente a la figura femenina y tal vez este hecho incide en las más recientes interpretaciones, antes aludidas, que se vienen vertiendo para estas figurillas. 
Junto a todo ello hay otro aspecto que tal vez no se ha resaltado lo suficiente y que no es otro que el que se refiere a como las manos de estos ídolos, al menos de la mayoría sino de todas, debieron soportar o llevar algún elemento de especial significación e identificación, armas o no, como se puede apreciar, según se ha repetido, tanto en el de Marroquíes Altos como en el de Llerena, y para los que estaría destinado el hueco en forma de $\mathrm{V}$ que se aprecia en los ejemplares de caliza marmórea de la Pijotilla, Rena (lám. 5) y el fragmento de tronco de Villafranca de los Barros (fig. 3)

\section{BIBLIOGRAFÍA}

ALMAGRO GORBEA, M. (1993): "Les stéles antrhropomorfes de la Péninsule Iberique”, Representations humaines du Néolithique a l"Age du Fer:123-139. Paris.

ALMAGRO GORBEA, M.J. (1973): Los ídolos del Bronce I hispano. B.P.H. XII. Madrid.

ARRIBAS, A. (1979): "El ídolo del Malagón (Cúllar-Baza, Granada)", Cuadernos de Prehistoria de la Universidad de Granada 2: 63-82.

BECARES PÉREZ, J. (1990): “Uniformidad conceptual de los ídolos del Calcolítico peninsular”, Zephyrus XLIII: 87-95.

BLANCO FREIJEIRO, A. (1962): "Die ältesten plastichen menschendarstellungen del Iberischen Halbinsel”, Madrider Mitteilungen 3: 12-20.

BLANCO FREIJEIRO, A. (1979): Historia de Sevilla I. La ciudad antigua (de la Prehistoria a los visigodos). Sevilla.

BRIARD, J. (1993): “Déesses brisées, Déesses armées, Déesses et Dieux du Néolithique a l’Age du Bronze”, Representations humaines du Néolithique a l'Age du Fer: 77-85. Paris.

BUENO, P. (1983): "Estatuas menhir y armas en el Norte de la península Ibérica", Zephyrus XXXVI: 153-159.

BUENO, P. (1990): “Statues menhirs et stéles anthropomorfes de la péninsule Iberique”, L'Anthorpologie 94: 85-110.

CHAPMAN, R. (1991): La formación de las sociedades complejas. El sureste de la península Ibérica en el marco del Mediterráneo occidental. Barcelona.

D’ANNA, A. (1977): Les statues-menhirs el stéles anthropomorfes du midi mediterranéen. Paris.

DUQUE ESPINO, D. (en prensa): "Estudio y evolución de un modelo territorial agrario: el poblamiento protohistórico de las Vegas bajas del Guadiana", Norba 15.

ENRÍQUEZ NAVASCUÉS, J.J. (1990): El Calcolítico o Edad del Cobre en la Cuenca media del Guadiana: los poblados. Badajoz.

ENRÍQUEZ NAVASCUÉS, J.J. (1997): "La Mérida prerromana y el poblamiento pre y protohistórico de su comarca", Mérida, Ciudad y Patrimonio 1: 29-43.

ENRÍQUEZ, J.J. e IÑESTA, J. (1995): "El poblado prehistórico de El Huertecillo en Llerena", Revista de Estudios Extremeños LI,1: 9-25.

ESCORIZA MATEU, T. (1991-92): "La formación social de Los Millares y las producciones simbólicas", Cuadernos de Prehistoria de la Universidad de Granada 16-17: 135-165.

FERNÁNDEZ GÓMEZ, F. y OLIVA, D. (1980): "Ídolos calcolíticos del Cerro de la Cabeza (Valencina de la Concepción)", Madrider Mitteilungen 21: 20-44.

FERNÁNDEZ MIRANDA, M. (1985): "Relaciones mediterráneas entre el cuarto y el segundo milenio”, XVIII Congreso Nacional de Arqueología.

GALLAY, R. (1986): L'Archéologie demain. Paris. 
GARCÍA SANJUÁN, L. y HURTADO, V. (1997): "Los inicios de la jerarquización social en el suroeste de la península Ibérica (c. 2500-1700 ane). Problemas conceptuales empíricos”, Homenaje a la Dra. Gil Macarell. Saguntum 30: 135-152.

GONÇALVES, V. (1997): "Manifestaçoes do sagrado na Pre-História do occidente peninsular 2. A propósito dos artafectos votivos de calcário das necropoles de Alcalar e Monte Velho", Setúbal Arqueológica 11-12: 199-216.

GUILLAINE, J. (1981): Premiers bergers el paysan de l'Occident méditerranée. Paris ( $2^{\mathrm{a}}$ ed.).

HURTADO, V. (1980): "Los ídolos calcolíticos de La Pijotilla (Badajoz)", Zephyrus XXX-XXXI: 165-203.

HURTADO, V. (1981): "Las figuras humanas del yacimiento de La Pijotilla (Badajoz)", Madrider Mitteilungen 22: 78-89.

HURTADO, V. (1995): "Interpretación sobre la dinámica cultural de la Cuenca Media del Guadiana(IV-II milenio ane)", Homenaje a Milagro Gil Mascarell. Extremadura Arqueológica V: 53-80.

HURTADO, V. dtor. (1995): El Calcolitico a debate. Sevilla.

HURTADO, V.y PERDIGONES, L. (1984): “Ídolos inéditos del Calcolítico del suroeste hispano”, Madrider Mitteilungen 24: 46-57.

IÑESTA MENA, J. (1995): “Un hallazgo excepcional: el ídolo de Llerena”, Revista de Ferias de Llerena: $11-14$. 


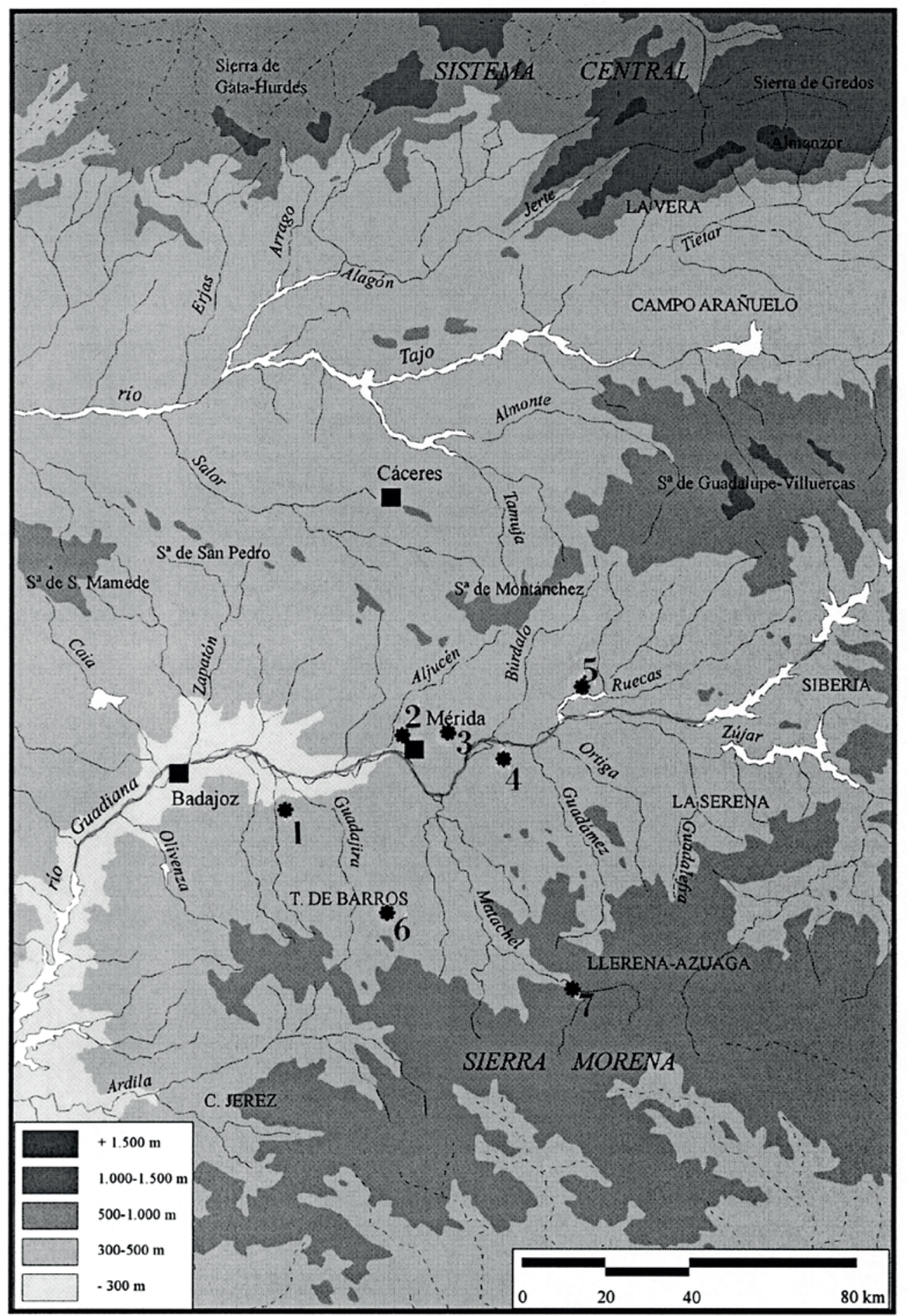

Figura 1: Dispersión de los ídolos con silueta antropomorfa en la Cuenca media del Guadiana.

1. La Pijotilla (Badajoz), 2. Las Lomas (Mérida), 3. Trujillanos 2(Trujillanos), 4. Travieso (Valdetorres),

5. La Habilla (Rena), 6. Villafranca de los Barros, 7. Llerena

ISSN: $1133-4525$ ISSN-e: 2255-3924 http://dx.doi.org/10.12795/spal.2000.i9.19 

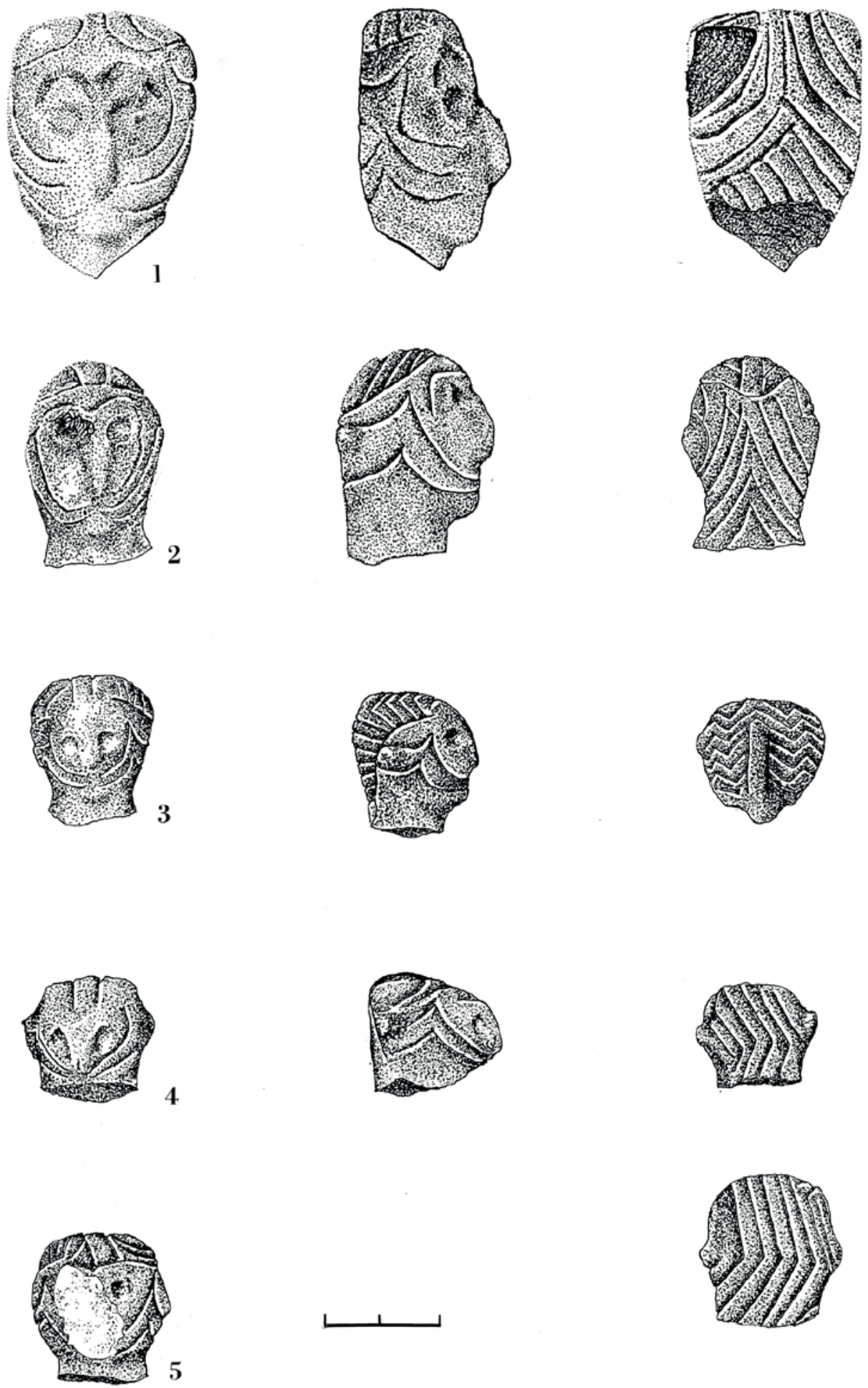

Figura 2: Cabezas de caliza marmórea: 1,3 y 5 Las Lomas; 2 y 4 Trujillanos 2

ISSN: 1133-4525 ISSN-e: 2255-3924

SPAL 9 (2000)

http://dx.doi.org/10.12795/spal.2000.i9.19 

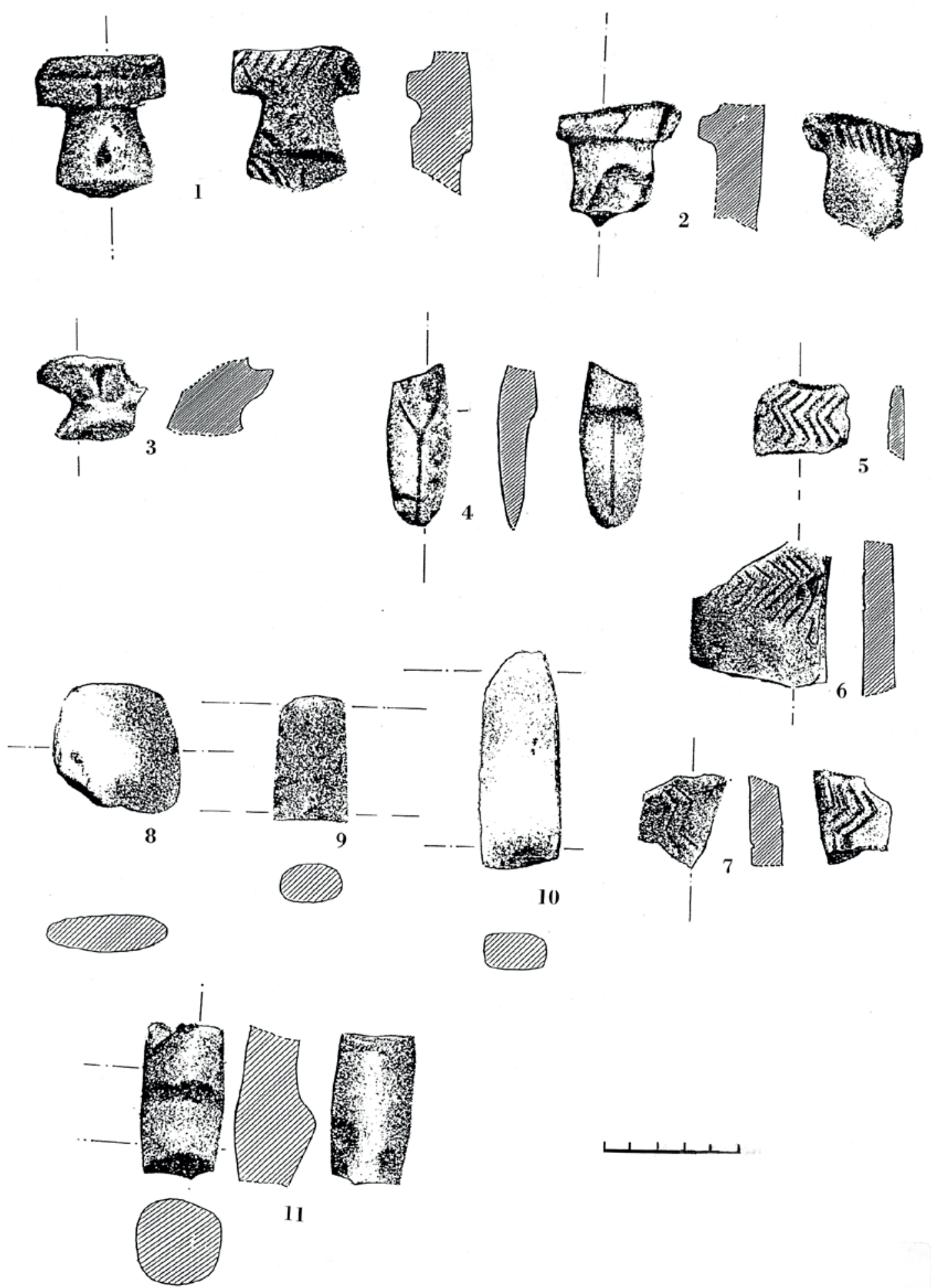

Figura 3: Fragmentos de ídolos en caliza marmórea: 1. Villafranca de los Barros, 2 y 5-11. Las Lomas, 3 y 4 . Travieso 

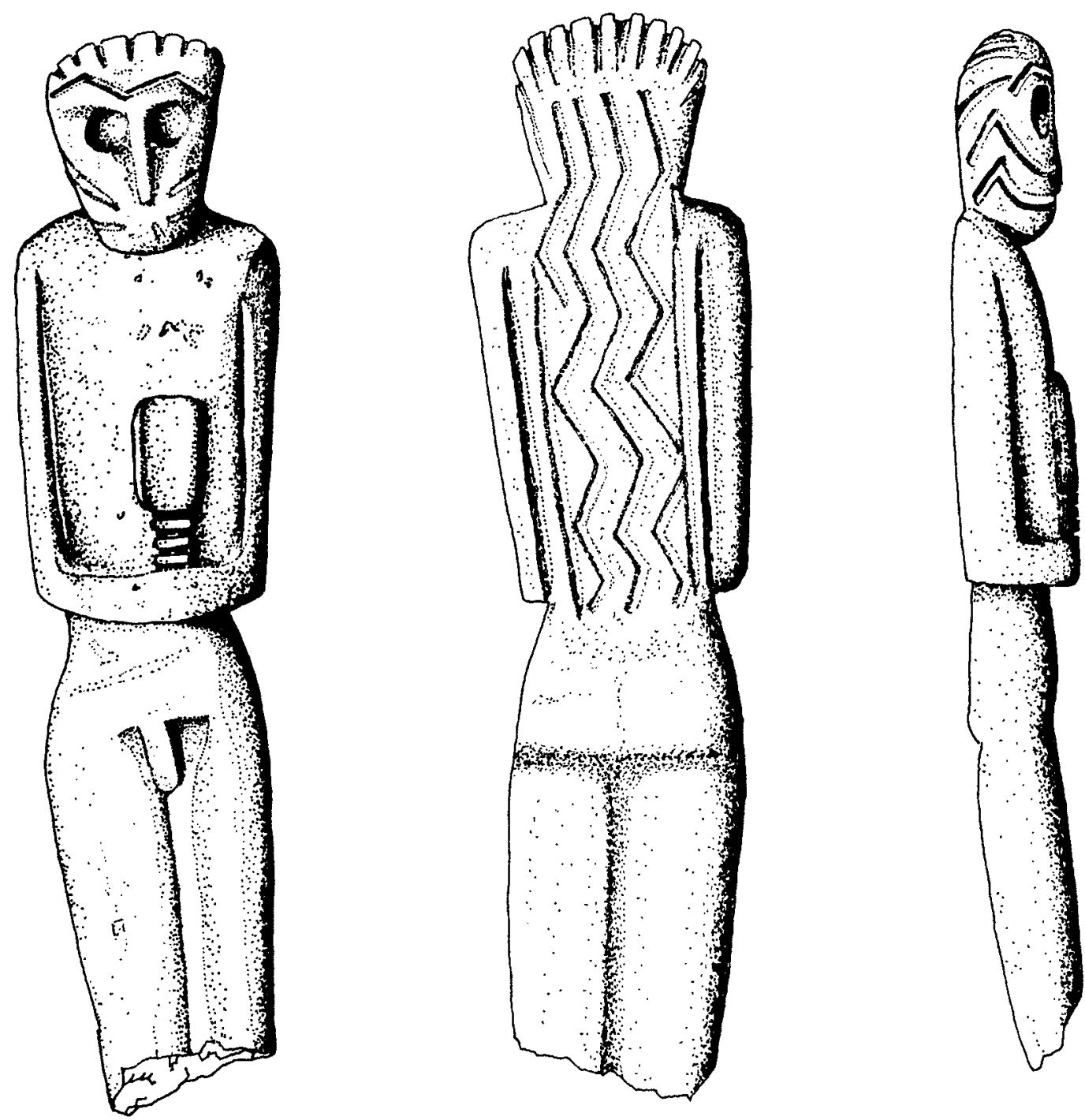

Figura 4: Ídolo de Llerena 


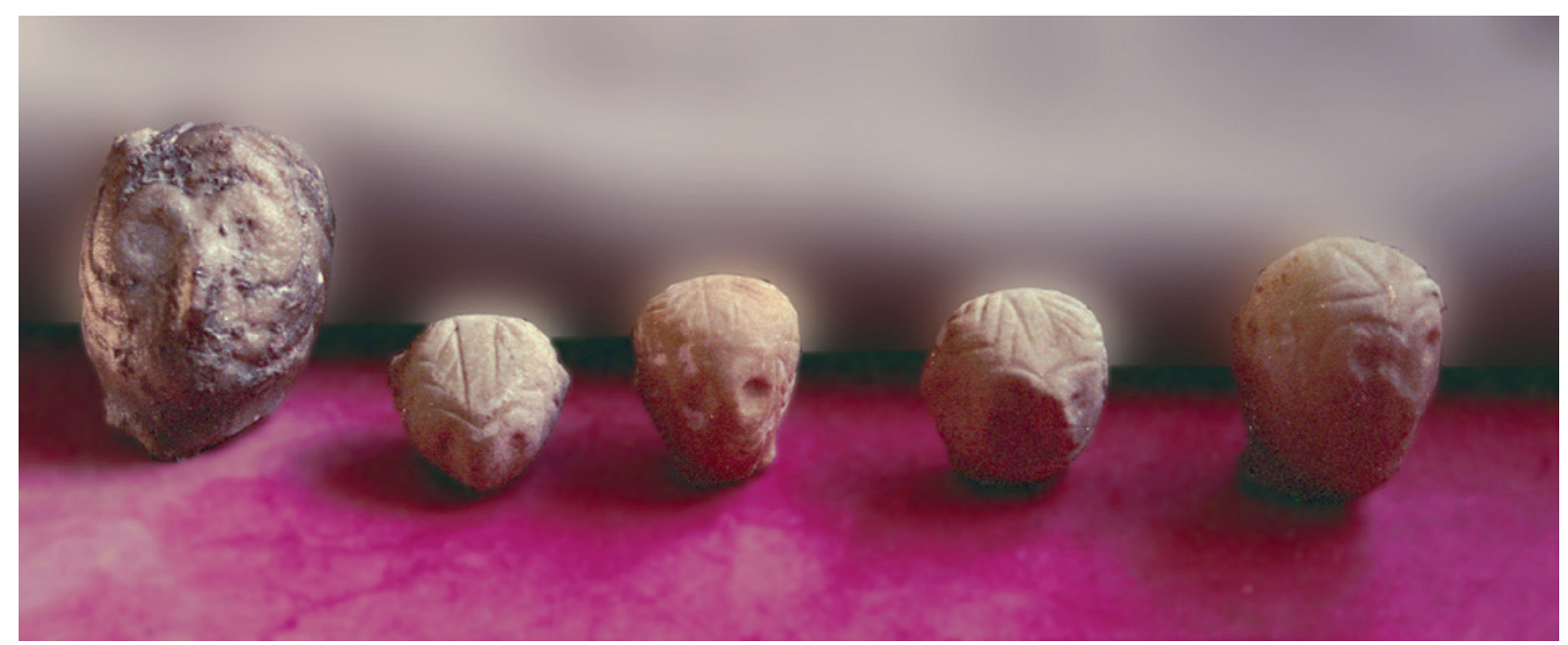

Lámina 1: Conjunto de las cinco cabezas antropomorfas

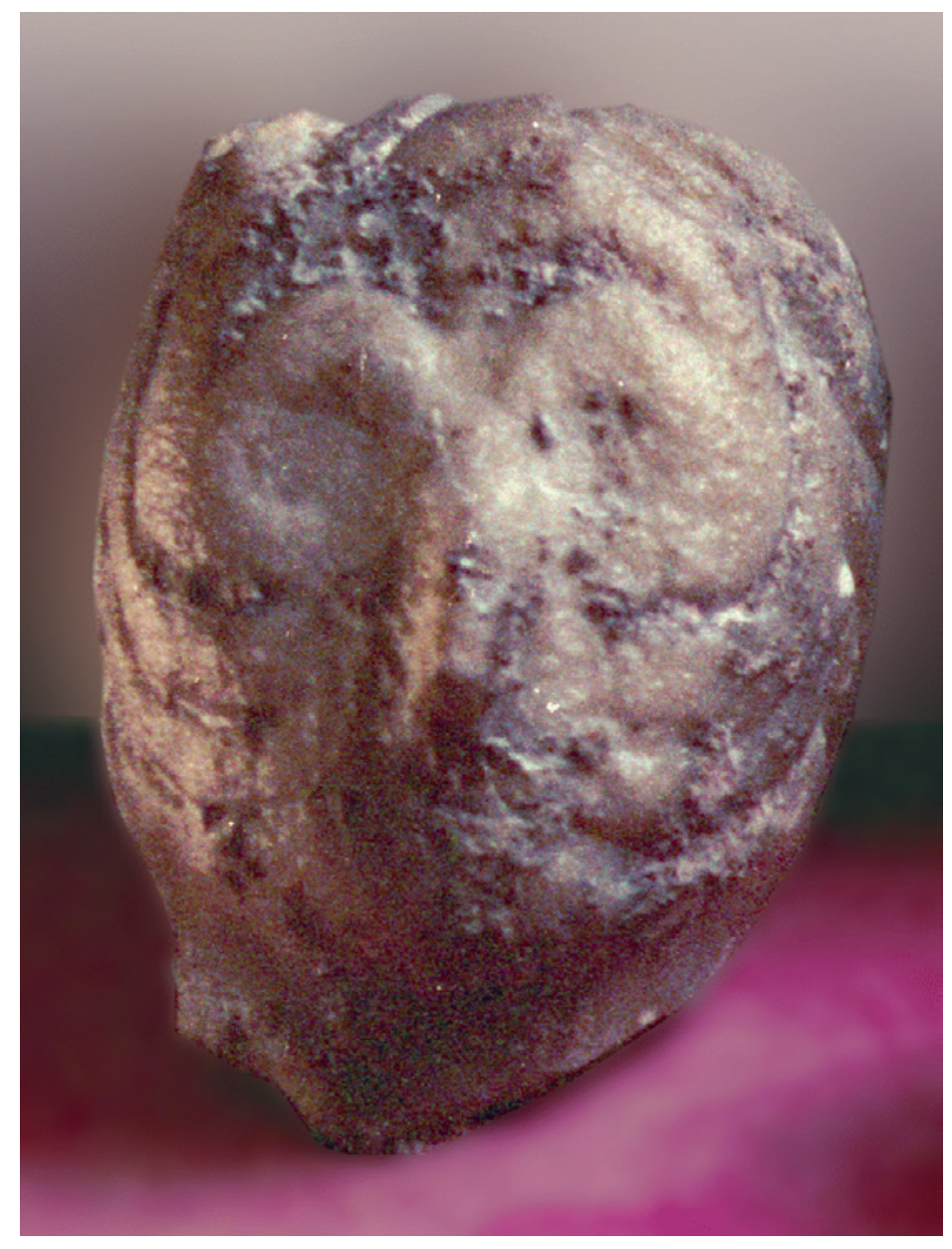

Lámina 2. Cabeza n ${ }^{\circ}$ (Las Lomas), vista frontal 


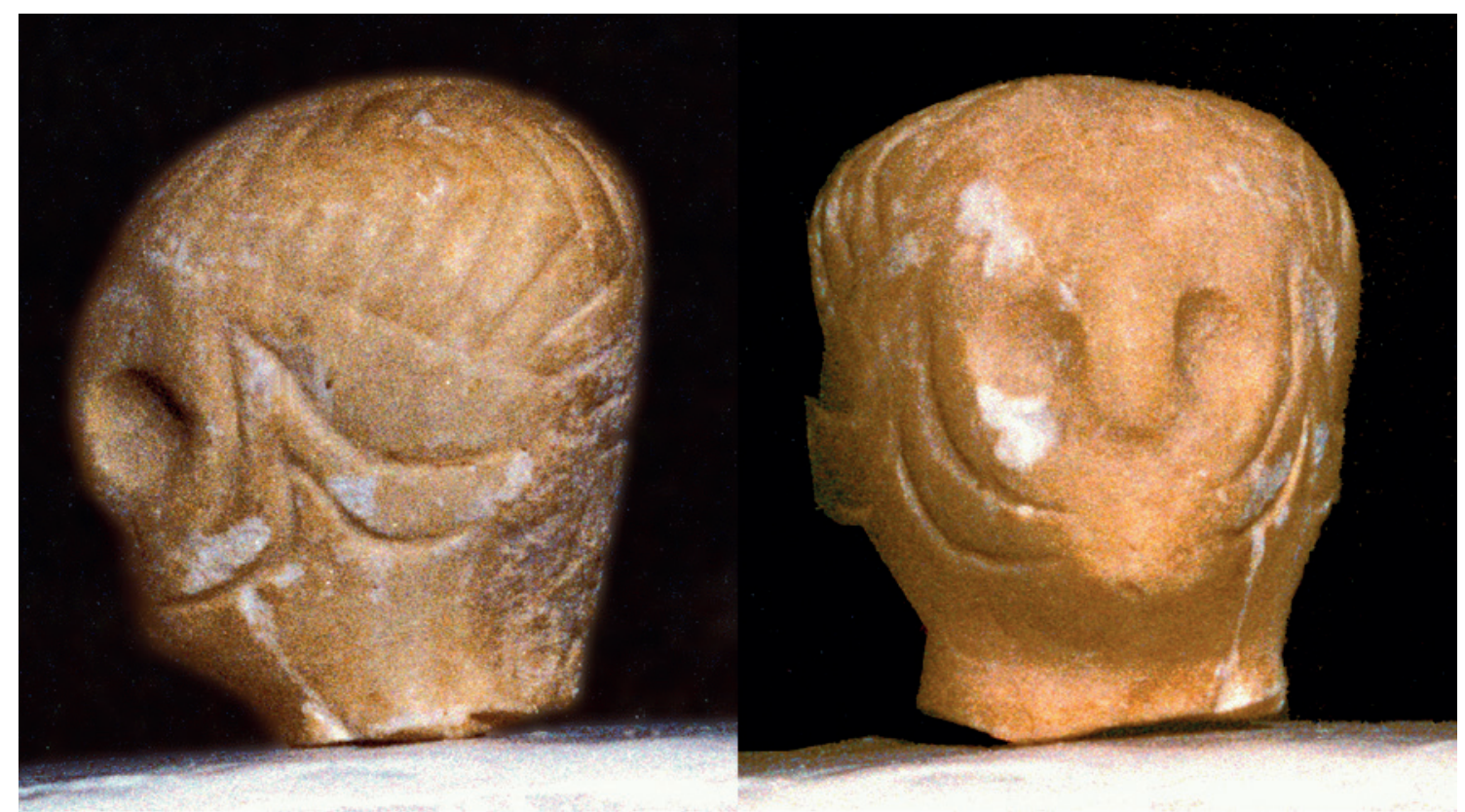

Lámina 3. Cabeza n ${ }^{\circ} 3$ (Las Lomas), vista frontal y lateral

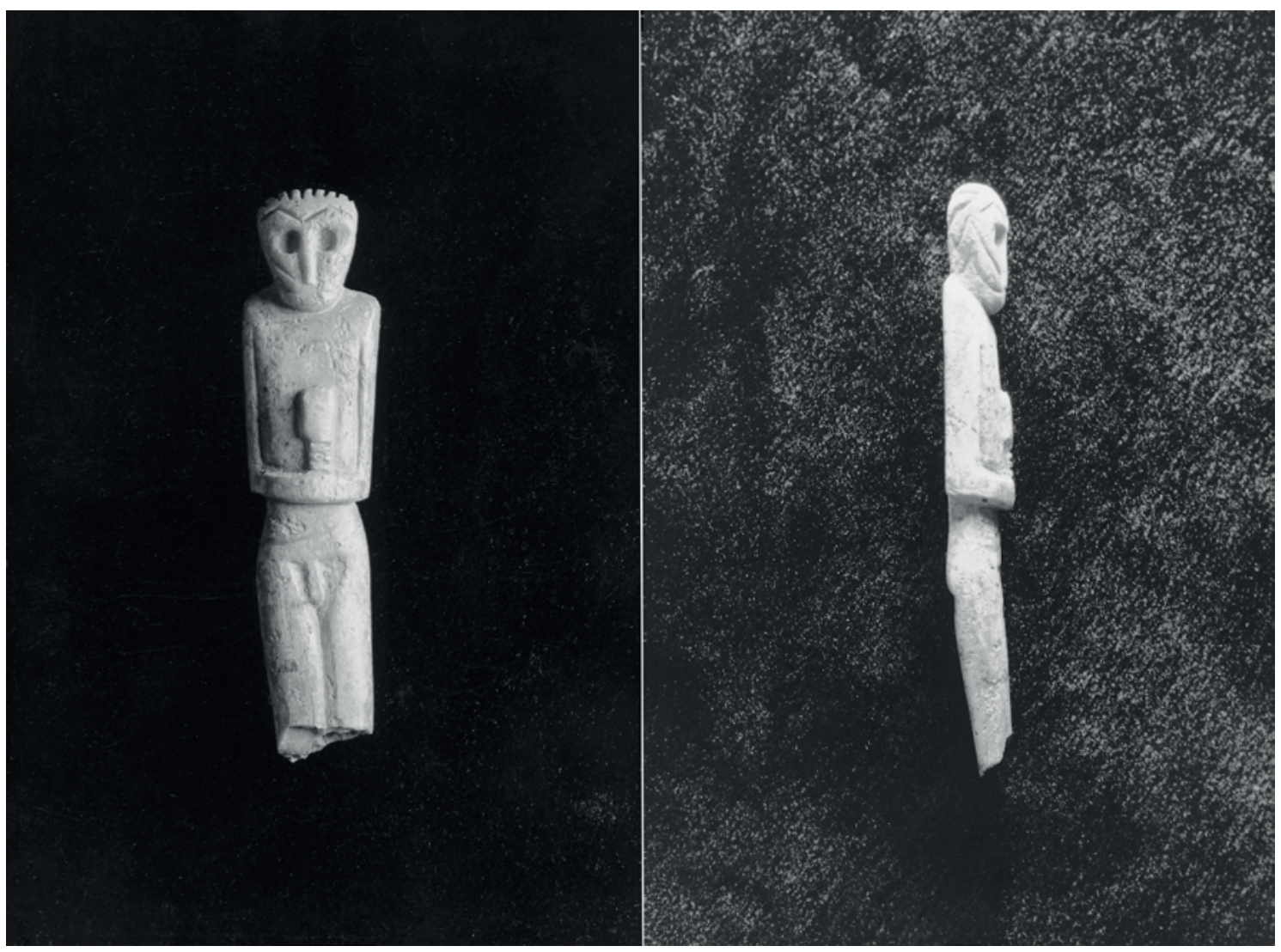

Lámina 4. Ídolo de Llerena, vista frontal y lateral (foto J. Iñesta)

ISSN: 1133-4525 ISSN-e: 2255-3924

SPAL $9(2000)$

http://dx.doi.org/10.12795/spal.2000.i9.19 


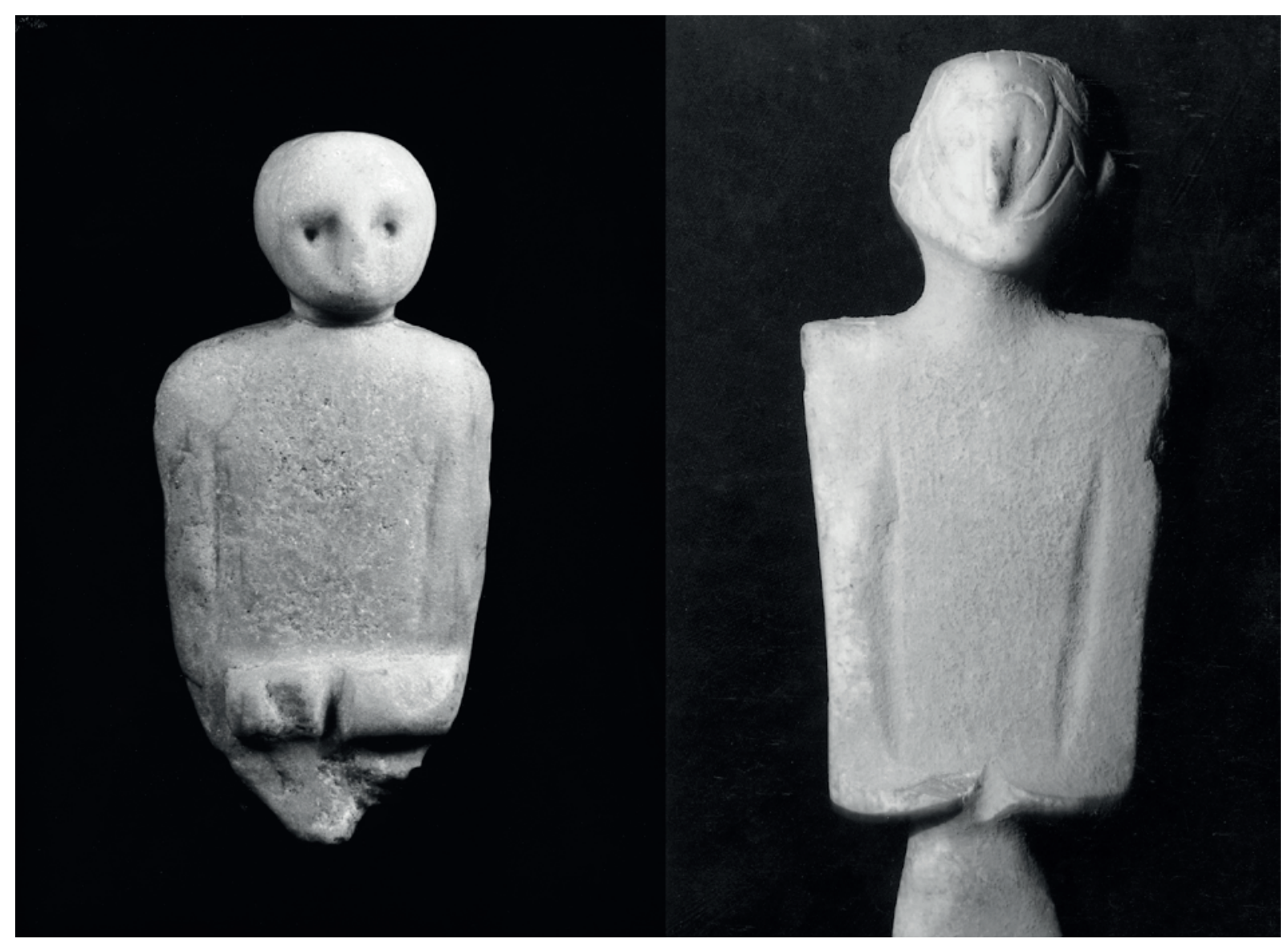

Lámina 5. Ídolo de La Pijotilla e ídolo de Rena (foto M.A.P.B.) 